\title{
Complications in adult spinal deformity surgery: an analysis of minimally invasive, hybrid, and open surgical techniques
}

\author{
Juan S. Uribe, M.D., ${ }^{1}$ Armen R. Deukmedjian, M.D., ${ }^{1}$ Praveen V. Mummaneni, M.D., ${ }^{2}$ \\ Kai-Ming G. Fu, M.D., ${ }^{3}$ Gregory M. Mundis JR., M.D., ${ }^{4}$ David O. OKonkwo, M.D., Ph.D., ${ }^{5}$ \\ Adam S. Kanter, M.D., ${ }^{5}$ Robert Eastlack, M.D.,${ }^{6}$ Michael Y. Wang, M.D. ${ }^{7}$ Neel Anand, M.D. ${ }^{8}$ \\ Richard G. Fessler, M.D., ${ }^{9}$ Frank La Marca, M.D.,${ }^{10}$ Paul Park, M.D..${ }^{10}$ Virginie Lafage, Ph.D., 11 \\ Vedat Deviren, M.D.,${ }^{12}$ Shay Bess, M.D. ${ }^{13}$ and Christopher I. Shaffrey, M.D.,${ }^{14}$ ON Behalf Of The \\ InTERnational Spine STUdy Group
}

${ }^{1}$ Department of Neurosurgery and Brain Repair, University of South Florida, Tampa; ${ }^{7}$ Departments of Neurological Surgery and Rehabilitation Medicine, University of Miami Miller School of Medicine, Miami, Florida; Departments of ${ }^{2}$ Neurosurgery and ${ }^{12}$ Orthopedic Surgery, University of California San Francisco; ${ }^{4}$ San Diego Center for Spinal Disorders; ${ }^{6}$ Department of Orthopedic Surgery, University of California San Diego, La Jolla; ${ }^{8}$ Department of Surgery, Cedars-Sinai Spine Center, Los Angeles, California; ${ }^{3}$ Department of Neurosurgery, Cornell University; ${ }^{\prime}$ Spine Division, NYU Hospital for Joint Diseases, New York, New York; ${ }^{5}$ Department of Neurological Surgery, University of Pittsburgh, Pennsylvania; ${ }^{9}$ Department of Neurological Surgery, Feinberg School of Medicine and McGaw Medical Center, Northwestern University, Chicago, Illinois; ${ }^{10}$ Department of Neurosurgery, University of Michigan, Ann Arbor, Michigan; ${ }^{13}$ Rocky Mountain Hospital for Children, Denver, Colorado; and ${ }^{14}$ Department of Neurological Surgery, University of Virginia, Charlottesville, Virginia

Object. It is hypothesized that minimally invasive surgical techniques lead to fewer complications than open surgery for adult spinal deformity (ASD). The goal of this study was to analyze matched patient cohorts in an attempt to isolate the impact of approach on adverse events. Methods. Two multicenter databases queried for patients with ASD treated via surgery and at least 1 year of follow-up revealed 280 patients who had undergone minimally invasive surgery (MIS) or a hybrid procedure $(\mathrm{HYB} ; \mathrm{n}=85)$ or open surgery $($ OPEN; $\mathrm{n}=195)$. These patients were divided into 3 separate groups based on the approach performed and were propensity matched for age, preoperative sagittal vertebral axis (SVA), number of levels fused posteriorly, and lumbar coronal Cobb angle (CCA) in an attempt to neutralize these patient variables and to make conclusions based on approach only. Inclusion criteria for both databases were similar, and inclusion criteria specific to this study consisted of an age $>45$ years, $\mathrm{CCA}>20^{\circ}, 3$ or more levels of fusion, and minimum of 1 year of follow-up. Patients in the OPEN group with a thoracic $\mathrm{CCA}>75^{\circ}$ were excluded to further ensure a more homogeneous patient population.

Results. In all, 60 matched patients were available for analysis (MIS $=20, \mathrm{HYB}=20$, OPEN $=20$ ). Blood loss was less in the MIS group than in the HYB and OPEN groups, but a significant difference was only found between the MIS and the OPEN group (669 vs 2322 $\mathrm{ml}, \mathrm{p}=0.001)$. The MIS and HYB groups had more fused interbody levels $(4.5$ and 4.1 , respectively) than the OPEN group $(1.6, \mathrm{p}<0.001)$. The OPEN group had less operative time than either the MIS or HYB group, but it was only statistically different from the HYB group (367 vs 665 minutes, $p<0.001)$. There was no significant difference in the duration of hospital stay among the groups. In patients with complete data, the overall complication rate was $45.5 \%$ (25 of 55). There was no significant difference in the total complication rate among the MIS, $\mathrm{HYB}$, and OPEN groups $(30 \%, 47 \%$, and $63 \%$, respectively; $\mathrm{p}=0.147)$. No intraoperative complications were reported for the MIS group, $5.3 \%$ for the HYB group, and $25 \%$ for the OPEN group ( $\mathrm{p}<0.03$ ). At least one postoperative complication occurred in $30 \%, 47 \%$, and $50 \%$ $(\mathrm{p}=0.40)$ of the MIS, HYB, and OPEN groups, respectively. One major complication occurred in $30 \%, 47 \%$, and $63 \%(\mathrm{p}=0.147)$ of the MIS, HYB, and OPEN groups, respectively. All patients had significant improvement in both the Oswestry Disability Index (ODI) and visual analog scale scores after surgery $(\mathrm{p}<0.001)$, although the MIS group did not have significant improvement in leg pain. The occurrence of complications had no impact on the ODI.

Conclusions. Results in this study suggest that the surgical approach may impact complications. The MIS group had significantly fewer intraoperative complications than did either the HYB or OPEN groups. If the goals of ASD surgery can be achieved, consideration should be given to less invasive techniques.

(http://thejns.org/doi/abs/10.3171/2014.3.FOCUS13534)

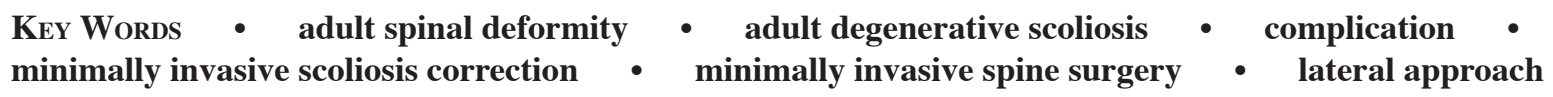

Abbreviations used in this paper: ALIF = anterior lumbar interbody fusion; ASA = American Society of Anesthesiologists; ASD = adult spinal deformity; $\mathrm{BMI}=$ body mass index $; \mathrm{CCA}=$ coronal Cobb angle; $\mathrm{EBL}=$ estimated blood loss; LIF = lateral interbody fusion; $\mathrm{LL}=$ lumbar lordosis; MIS = minimally invasive surgery; $\mathrm{ODI}=$ Oswestry Disability Index; OR = operating room; $\mathrm{PI}=$ pelvic incidence; $\mathrm{PPS}=$ percutaneous pedicle screw; $\mathrm{PT}=$ pelvic tilt; $\mathrm{SVA}$ $=$ sagittal vertical axis; $\mathrm{TK}=$ thoracic kyphosis; $\mathrm{TLIF}=$ transforami nal lumbar interbody fusion; VAS = visual analog scale.
$\mathrm{O}$ VER the past several decades, surgical treatment options for adult spinal deformity (ASD) have expanded, including both minimally invasive and open techniques. . $^{3,12,14,18,27}$ Determining the most suitable approach in patients should take into account the risks and benefits of each surgical technique. Unfortunately, studies comparing the different operative techniques are lacking. Moreover, outcomes and complications of ASD 
are largely reported in terms of patient characteristics following traditional open techniques with little published data about minimally invasive procedures. ${ }^{27,32}$

Open techniques require extensive soft tissue mobilization (Fig. 1A), and long-segment fusions are associated with complication rates ranging from $10 \%$ to $75 \% .4,8,10,11$, 15,19,23,25,30,31,33 Minimally invasive surgery (MIS) for ASD correction has become increasingly popular. As reported by Smith et al., outcome measures after ASD surgery in elderly patients improve more dramatically than in younger patients, and with an increasing elderly population, minimally invasive surgical correction will remain an important option. ${ }^{32}$ Less disruptive procedures are focused on using combined approaches with a variety of techniques: minimally invasive transpsoas lateral interbody fusion (LIF), mini-open transforaminal lumbar interbody fusion (TLIF), anterior lumbar interbody fusion (ALIF), presacral interbody fusion (AxiaLIF, TranS1 Inc.), and minimally invasive pedicle screw fixation (Fig. 1B). An MIS aims to diminish the soft tissue disruption of the surgical approach without compromising the objectives of deformity surgery, that is, stabilization of the deformity, global and sagittal realignment, and arthrodesis. On the other hand, an intermediate "hybrid" option using combined open and minimally invasive techniques, such as lateral transpsoas fusions and/or mini-open TLIF, followed by posterior laminectomy and/or osteotomies, has potential benefits related to construct durability, higher fusion rates, and deformity correction.

Minimally invasive procedures offer several hypothetical advantages over traditional open surgical approaches, including decreased muscle dissection causing reduced paraspinal atrophy, decreased rates of infection, shorter time to narcotic independence, and decreased health care costs as well as the ability to place an interbody graft to increase fusion. ${ }^{17,18,20,24,27,28,36}$ Potential disadvantages may include limited sagittal correction. Complications of these increasingly applied procedures in the treatment of ASD must be examined, compared, and reported.

To determine whether complications in ASD surgery are related to surgical approach, we retrospectively analyzed a prospective, propensity-matched cohort of patients with similar surgically treated levels.
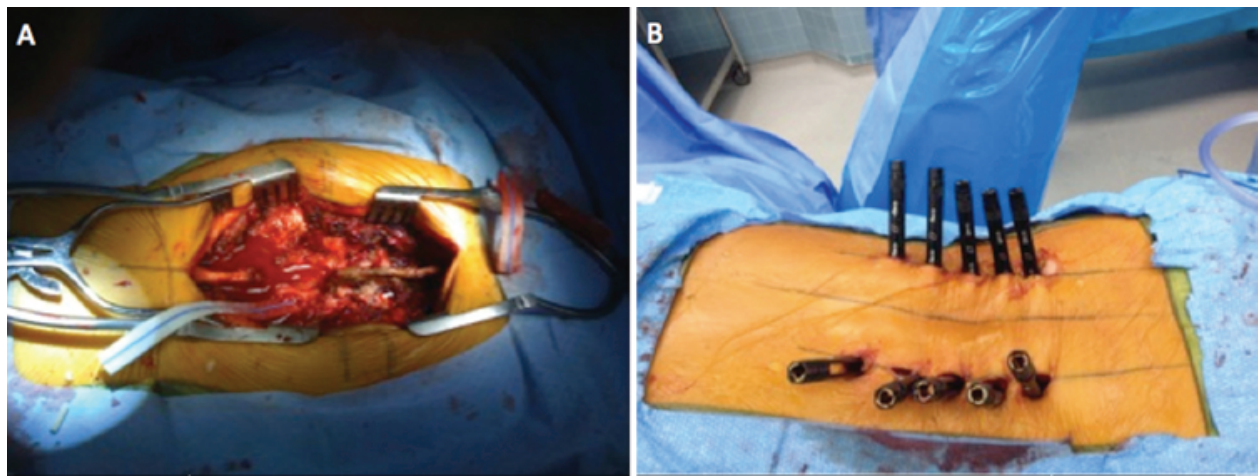

FIG. 1. A: Intraoperative photograph of an open surgical approach for the correction of ASD. Note the extensive soft tissue and muscle release needed for the exposure. B: Intraoperative photograph of a posterior percutaneous screw fixation procedure, which was done following a 3-level lateral interbody fusion. Note the reduction in muscle dissection and exposure compared with that in the open approach.
We conducted a retrospective review of one prospectively and one retrospectively collected multicenter database contributed to by 16 participating institutions. An initial query for patients with ASD treated via surgery and at least 1 year of follow-up revealed 280 patients who had undergone MIS or a hybrid procedure (HYB; $\mathrm{n}=85$ ) or open techniques $(\mathrm{n}=195)$, with a mean age of $63 \pm 8.9$ years (mean \pm standard deviation). The OPEN group contained patients who had undergone open pedicle screw fixation with or without interbody fusion. The MIS group consisted of patients who had undergone a stand-alone transpsoas LIF, LIF with percutaneous pedicle screw (PPS) fixation, and minimally invasive TLIF with PPS fixation. A third and final group included patients who underwent a HYB approach consisting of both open and minimally invasive techniques (minimally invasive LIF/TLIF with open pedicle screw fixation and/or laminectomy and/or osteotomy). Study inclusion criteria for the retrospective MIS/HYB database were defined as an age $>18$ years and one of the following factors: coronal Cobb angle (CCA) $>20^{\circ}, \geq 3$ fused intervertebral segments, sagittal vertical axis (SVA) $>5$ $\mathrm{cm}$, pelvic tilt $>20^{\circ}$, or at least 1 year of follow-up. Study inclusion criteria for the prospectively enrolled OPEN patients were defined as an age $>18$ years and one of the following factors: CCA $>20^{\circ}$, SVA $>5 \mathrm{~cm}$, pelvic tilt (PT) $>25^{\circ}$, or thoracic kyphosis $(\mathrm{TK})>60^{\circ}$. Propensity matching was used to identify 3 groups of patients with statistically equivalent profiles, deformities, and extent of fusion. Our subgroups were propensity matched for preoperative age, preoperative SVA, number of levels fused posteriorly, and preoperative major lumbar CCA. All patients younger than 45 years were excluded, as were OPEN patients with a thoracic CCA of $>75^{\circ}$. Subgroup analysis was performed to assess the incidence of major clinical and radiographic complications, as defined by Glassman et al. ${ }^{19}$ Complications were analyzed and classified as intraoperative or postoperative and major or minor (Table 1).

\section{Data Collection}

Outcomes for the 3 study cohorts were assessed based

\section{Study Design and Group Definition}




\section{Complications in spinal deformity surgery}

TABLE 1: List of complications in patients who underwent surgery for ASD*

\begin{tabular}{ccc}
\hline Complication & Minor & Major \\
\hline intraop & $\begin{array}{c}\text { CSF leak, excessive bleeding, intraop coagulopathy, fracture of } \\
\text { posterior element, breach of pedicle, fracture of vertebral } \\
\text { body }\end{array}$ & $\begin{array}{c}\text { bowel/bladder injury, cardiac arrest, injury to cauda equina, } \\
\text { death, inadvertent extubation, malignant hyperthermia, injury } \\
\text { to nerve root, vascular/visceral injury }\end{array}$ \\
& $\begin{array}{c}\text { superficial infection, radiculopathy, sensory deficit, skin compli- } \\
\text { postop }\end{array}$ & $\begin{array}{c}\text { bot/bladder deficit, DVT/PE, deep infection (wound dehis- } \\
\text { cence), death, motor deficit, myocardial infarction, neurologi- }\end{array}$ \\
& cal superficial thrombophlebitis, excessive bleeding & cal complication, optic deficit, pneumonia, reintubation, \\
& & sepsis, stroke, instrumentation failure \\
\hline
\end{tabular}

* Based on data from the Adult Deformity Outcomes Study (Glassman et al., 2007). DVT = deep venous thrombosis; PE = pulmonary embolism.

on 1-year postoperative outcome variables, including visual analog scale (VAS) scores for both back and leg and the Oswestry Disability Index (ODI). Demographic and intraoperative data were also recorded for each group, including age, comorbidities, American Society of Anesthesiologists (ASA) physical status score, body mass index (BMI), estimated blood loss (EBL), operating room (OR) time, duration of hospital stay, and number of levels fused both posteriorly and via an interbody graft. Excessive blood loss ( $>4 \mathrm{~L}$ ) was characterized as a minor complication. All patients had 36-in standing scoliosis radiographs; recorded preoperative and postoperative radiographic parameters included CCAs of the thoracic and lumbar spine, TK, pelvic incidence (PI) minus lumbar lordosis (LL), PT, and SVA (Fig. 2).

\section{Statistical Analysis}

Patients were matched using propensity scores by ap-
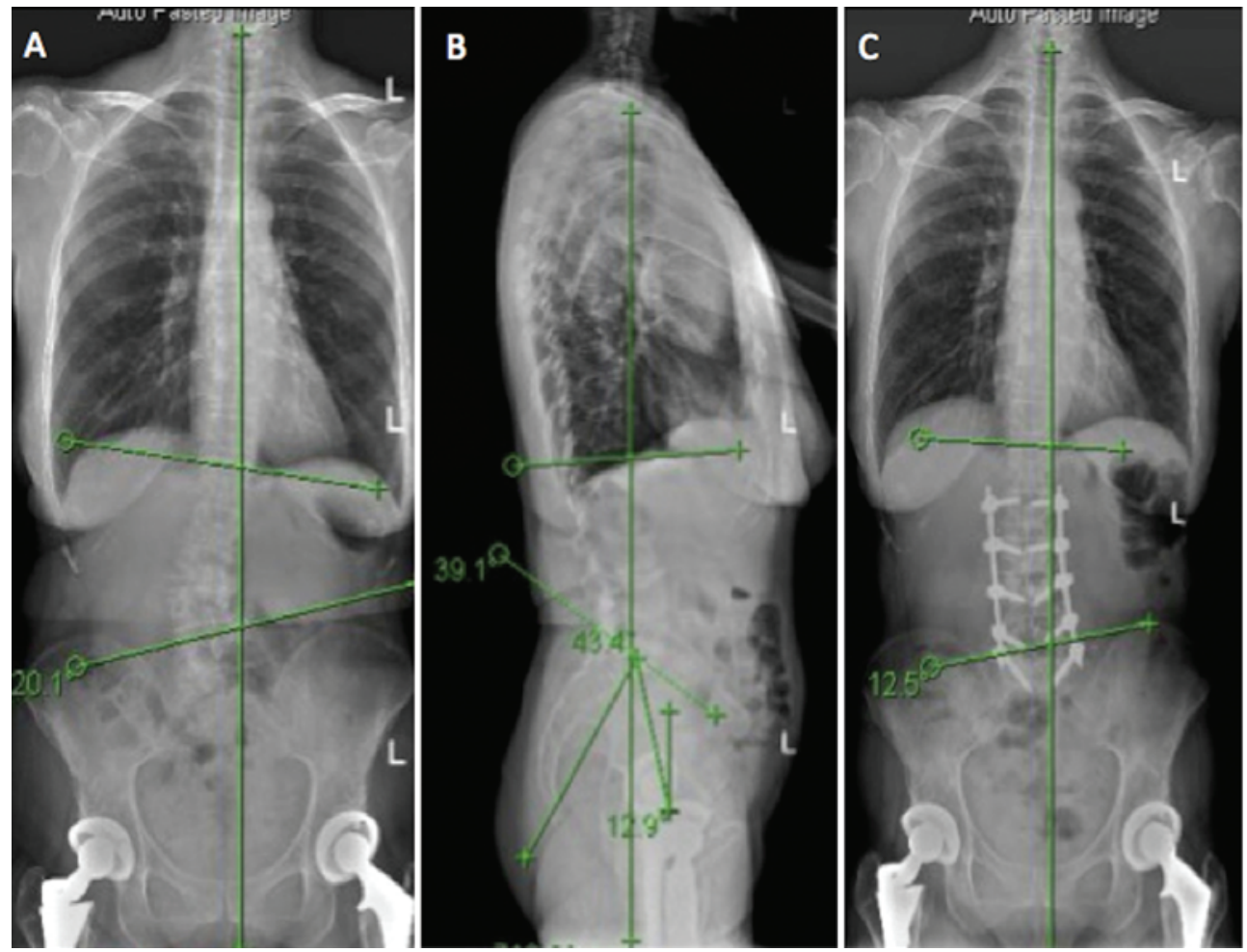

plying linear regression. Propensity matching took into account age, SVA, number of levels fused posteriorly, and the lumbar CCA. Patients whose data were matched had the same propensity to undergo one of the 3 approaches (OPEN, HYB, MIS) based on their preoperative profile, thus creating a more homogeneous population. The mean and standard deviation were used to describe continuous variables, and frequency analyses were used for categorical variables. Comparisons among the three groups were performed using ANOVA and chi-square analysis. Change between preoperative and postoperative parameters was analyzed using a paired t-test. All complications were recorded and compared between groups using the chi-square test. A p value of 0.05 was significant.

\section{Results}

Of 280 patients undergoing ASD surgery in the da-

FIG. 2. Preoperative ( $A$ and $B$ ) and postoperative ( $C$ and $D)$ 36-in long-cassette radiographs obtained in a patient who underwent a minimally invasive correction of ASD. The radiographic parameters of LL, PI, SVA, and TK were measured. 


\section{J. S. Uribe et al.}

tabase, 60 remained after propensity matching to control for age, SVA, number of levels fused posteriorly, and lumbar CCA.

\section{Demographic Data}

No significant differences existed among the groups with regard to sex $(88 \%$ female for the entire cohort, $90 \%$ for the OPEN and HYB groups, and $85 \%$ for the MIS group), age (mean 63 years), ASA score (mean 2.2), number of comorbidities (mean 2.3 per patient), and history of previous spine surgery (65\% of cases were primary; Table 2). The MIS group had significantly lower BMI when compared with the HYB group (23.9 vs $28.1 \mathrm{~kg}$ / $\left.\mathrm{m}^{2}, \mathrm{p}=0.03\right)$.

\section{Intraoperative Data}

Table 3 displays intraoperative data from the 3 cohorts, demonstrating that the MIS and HYB groups had more interbody levels fused (4.5 and 4.1, respectively) than the OPEN group $(1.6, \mathrm{p}<0.001)$. There was less EBL in the MIS group $(669 \mathrm{ml})$ than in the OPEN group (2322 $\mathrm{ml}, \mathrm{p}<0.001)$. Excessive blood loss $(>4 \mathrm{~L})$ was recorded as a complication in 3 patients in the OPEN group (15\%). Comparing OR times, we noted that the OPEN procedures were on average shorter than the HYB procedures (367 minutes vs 665 minutes, $\mathrm{p}<0.001$ ) but not significantly different from the MIS procedures (507 minutes). There was also no significant difference in terms of the length of stay (mean 8.5 days with a range of 1-23 days).

\section{Radiographic Parameters}

Preoperatively, there were no significant differences except that the MIS and HYB groups had a smaller thoracic CCA than the OPEN group $\left(16^{\circ} / 15^{\circ}\right.$ vs $28^{\circ}$, p < 0.008; Tables 4 and 5). Postoperatively, the OPEN group had a smaller PI-LL mismatch than the MIS group $\left(6^{\circ}\right.$ vs $17^{\circ}, \mathrm{p}<0.03$ ). Also postoperatively, the OPEN group had a significantly greater lumbar CCA than the MIS and HYB groups $\left(21^{\circ}\right.$ vs $\left.11^{\circ} / 10^{\circ}, \mathrm{p}<0.005\right)$ and greater thoracic $\mathrm{CCA}\left(21^{\circ}\right.$ vs $\left.12^{\circ} 6^{\circ}, \mathrm{p}<0.003\right)$. In all 3 groups, there was a significant decrease in the lumbar CCA, with no significant changes in the PT for all groups. The HYB and OPEN groups demonstrated a significant decrease in the PI-LL mismatch, thoracic CCA, and SVA and an increase in the TK. With respect to pre- versus postoperative changes, the HYB group had a significantly greater change in the lumbar CCA than the OPEN group $\left(-24^{\circ}\right.$ vs $\left.-14^{\circ}, \mathrm{p}=0.02\right)$. The OPEN group had a greater change in the PI-LL mismatch than the MIS group $\left(-14^{\circ} \mathrm{vs}-3^{\circ}\right.$, $\mathrm{p}=0.04$ ).
TABLE 3: Intraoperative data for 60 patients who underwent surgery for ASD

\begin{tabular}{lcccc}
\hline Group & $\begin{array}{c}\text { No. of Levels Fused } \\
\text { (posterior/interbody) }\end{array}$ & EBL $(\mathrm{ml})$ & $\begin{array}{c}\text { OR Time } \\
(\mathrm{min})\end{array}$ & $\begin{array}{c}\text { Length of } \\
\text { Stay (days) }\end{array}$ \\
\hline MIS & $5.6 / 4.5$ & 669 & 507 & 6.4 \\
HYB & $6.4 / 4.1$ & 1518 & 665 & 4.5 \\
OPEN & $5.2 / 1.6$ & 2322 & 367 & 7.4 \\
\hline
\end{tabular}

\section{Clinical Outcomes}

There were no significant differences among the groups in terms of preoperative and postoperative scores for VAS back, VAS leg, and ODI (Table 6). All 3 groups had a statistically significant decrease in their VAS and ODI scores, except the MIS group did not see a significant improvement with leg pain postoperatively.

\section{Complications}

On average, there were 1.06 complications per patient for the OPEN group, 0.84 per patient in the HYB group, and 0.30 per patient in the MIS group $(p=0.04)$ (Table 7 ). When comparing the OPEN group to the MIS group, there were no significant differences for postoperative complications or major complications, but there were more intraoperative complications $(0.3$ vs $0, p=0.03)$ and minor complications $(0.4$ vs $0, \mathrm{p}=0.4)$ per patient. Overall, $45.5 \%$ of patients had at least one complication, and $46 \%$ of the 60 patients had a major complication, without any significant differences among the 3 groups $(62.5 \%$ for the OPEN group vs $30 \%$ for the MIS group, $p=0.147$ ). The comparison of intraoperative complications revealed that the MIS group had significantly fewer complications than the HYB group, which in turn had fewer complications than the OPEN group. The analysis of individual complications did not reveal any significant differences between the groups, except some HYB patients experienced deep venous thrombosis $(15.8 \%$ vs $0 \%$ in MIS and OPEN groups, $\mathrm{p}=0.05$ ).

\section{Discussion}

Adult spinal deformity is one of the most challenging disorders for a spine surgeon to treat and may be associated with a substantial number of perioperative and postoperative complications..$^{10,19,21-23,25,29}$ Factors associated with higher complication rates include comorbidities, age, smoking, osteoporosis, long fusions, and excessive blood loss..$^{7,15,16,26}$ Glassman et al. ${ }^{19}$ demonstrated that major complications in their cohort led to worse outcomes,

TABLE 2: Summary of demographic data among 60 patients who underwent surgery for ASD

\begin{tabular}{lcccccc}
\hline Group & No. of Patients & Mean Age $(\mathrm{yrs})$ & Sex $(\% \mathrm{M}: \% \mathrm{~F})$ & ASA Score & BMI $\left(\mathrm{kg} / \mathrm{m}^{2}\right)$ & No. of Comorbidities \\
\hline MIS & 20 & 64.0 & $15: 85$ & 2.5 & $23.9^{*}$ & 1.8 \\
HYB & 20 & 69.1 & $10: 90$ & 2.1 & 28.1 & 3.2 \\
OPEN & 20 & 61.6 & $10: 90$ & 2.2 & 27.3 & 2.0 \\
\hline
\end{tabular}

* The only significant difference was in BMI between MIS and HYB groups $(p=0.03)$. 
TABLE 4: Preoperative and postoperative radiographic parameters among patients who underwent surgery for ASD*

\begin{tabular}{|c|c|c|c|}
\hline \multirow[b]{2}{*}{ Parameter } & \multicolumn{3}{|c|}{ Group } \\
\hline & MIS & HYB & OPEN \\
\hline \multicolumn{4}{|l|}{ CCA-lumbar $\left({ }^{\circ}\right)$} \\
\hline preop & 33 & 34 & 36 \\
\hline postop & 11 & 10 & 21 \\
\hline$\Delta$ & -22 & -24 & -14 \\
\hline$p$ value & $<0.001$ & $<0.001$ & $<0.001$ \\
\hline \multicolumn{4}{|c|}{ CCA-thoracic $\left({ }^{\circ}\right)$} \\
\hline preop & 16 & 15 & 28 \\
\hline postop & 12 & 6 & 21 \\
\hline$\Delta$ & -4 & -9 & -7 \\
\hline$p$ value & 0.051 & $<0.001$ & 0.003 \\
\hline \multicolumn{4}{|l|}{$\mathrm{TK}\left({ }^{\circ}\right)$} \\
\hline preop & 33 & 32 & 33 \\
\hline postop & 36 & 40 & 43 \\
\hline$\Delta$ & 3 & 9 & 9 \\
\hline$p$ value & 0.274 & 0.012 & 0.001 \\
\hline \multicolumn{4}{|l|}{ PI-LL $\left({ }^{\circ}\right)$} \\
\hline preop & 20 & 26 & 20 \\
\hline postop & 17 & 11 & 6 \\
\hline$\Delta$ & -3 & -12 & -14 \\
\hline$p$ value & 0.402 & 0.006 & $<0.001$ \\
\hline \multicolumn{4}{|l|}{ PT $\left({ }^{\circ}\right)$} \\
\hline preop & 29 & 36 & 29 \\
\hline postop & 26 & 37 & 25 \\
\hline$\Delta$ & -3 & -1 & -4 \\
\hline$p$ value & 0.337 & 0.865 & 0.138 \\
\hline \multicolumn{4}{|l|}{ SVA (mm) } \\
\hline preop & 28 & 61 & 65 \\
\hline postop & 31 & 34 & 35 \\
\hline$\Delta$ & -2 & -29 & -30 \\
\hline$p$ value & 0.795 & 0.010 & 0.020 \\
\hline
\end{tabular}

* Boldface indicates significant values.

as evidenced by lower 12-Item Short-Form Health Survey scores at 1 year postoperatively. However, Albert et al. ${ }^{2}$ reported no change in outcome score (36-Item Short-Form Health Survey) in patients with complications undergoing ASD correction. The current study is the first to examine the incidence of complications associated with surgical approach in 3 cohorts of patients propensity matched for age, outcome (pre- compared with postoperative ODI), and coronal and sagittal radiographic parameters.

Innovation in operative technique, along with an improved understanding of biomechanics and surgical outcomes, has permitted the development of several surgical approaches in treating adult scoliosis. To determine the ideal approach in treating adults with spinal deformity, it is necessary to know if the presence of complications is related to approach or to patient characteristics. Unfortunately, outcomes for adult deformity surgery are largely reported in reference to a specific surgical technique and are not applicable to other procedures. This study is among the first to compare complications of open versus less invasive surgical approaches. To differentiate complications and compare different techniques, propensity matching was used to compare homogeneous groups.

Open surgery is the most studied technique but is also associated with the greatest morbidity. Bhagat et al. ${ }^{6}$ recently reported on a cohort of 48 patients who had open surgical correction of ASD and a 39.5\% major complication rate, whereas Cho et al. ${ }^{10}$ reported a $34.4 \%$ major complication rate in adult deformity revision surgery. In our study we noted an incidence of $46 \%$ for any (intraoperative and postoperative) complication for all 3 groups combined, with the highest incidence in the OPEN group, albeit not statistically significant (MIS 30\%, HYB 47\%, OPEN 63\%, $\mathrm{p}=0.147$ ). Along these same lines, the MIS group had the fewest, and the OPEN group had the most, postoperative complications ( $30 \%$ vs $50 \%$ ), major complications (30\% vs 63\%), and minor complications (0\% vs $25 \%$ ); however, these differences were not statistically significant. The only statistically significant difference in regard to complication rates was the intraoperative complications between the MIS and the OPEN groups ( $0 \%$ vs $25 \%, p=0.03)$. However, the majority $(15 \%)$ of intraoperative complications in the OPEN group were excessive blood loss (> $4 \mathrm{~L})$, which has a questionable impact on short- and long-term outcomes. ${ }^{34}$ The HYB group's rate of complications fell between the MIS and OPEN groups. A lack of power due to the small cohort is probably why the majority of significant differences were not found between the groups. Note that MIS procedures to treat ASD are relatively new. Sixteen sites contributed to the databases used in this study to pool cases since there is not a large volume of these cases with a long follow-up at this time.

Few studies have evaluated outcomes and the incidence of complications in MIS for ASD. ${ }^{5,9,38,39}$ In the present study we defined the MIS group as those who underwent stand-alone LIF, LIF with PPS fixation, minimally invasive TLIF with PPS, and percutaneous presacral interbody fusion. This group overall had less blood loss $(669 \mathrm{ml})$ than the OPEN group $(2322 \mathrm{ml}, \mathrm{p}<0.001)$ but longer OR time (507 vs 367 minutes, $\mathrm{p}=0.10$ ). As described above, there was a statistically significantly lower rate of intraoperative complications with this group as well. We believe this lower rate can be explained by less tissue disruption and lower blood loss. In addition, the study design comparing these 2 disparate databases may be a factor in this statistical difference. The most frequent complication reported in the MIS group was implant failure (8\%). Our study supports previously reported lower infection rates and intraoperative blood loss associated with MIS. 17,18,20,27,28,38

Combining traditional open deformity correction with MIS techniques is an alternative method of achieving the goals of deformity surgery. In our study the incidence of complications in the HYB group was between the rates for the MIS and OPEN subgroups. Operative time for the HYB subgroup was significantly longer $(665$ minutes) than that for the OPEN group $(\mathrm{p}<0.001)$. This is probably attributable to the increased number of inter- 
TABLE 5: Preoperative and postoperative radiographic parameters among groups that underwent surgery for ASD*

\begin{tabular}{|c|c|c|c|c|c|c|}
\hline \multirow[b]{2}{*}{ Parameter } & \multicolumn{2}{|c|}{ Preop } & \multicolumn{2}{|c|}{ Postop } & \multicolumn{2}{|c|}{$\Delta$} \\
\hline & $\begin{array}{c}\text { Mean } \\
\text { Difference }\end{array}$ & p Value & $\begin{array}{c}\text { Mean } \\
\text { Difference }\end{array}$ & p Value & $\begin{array}{c}\text { Mean } \\
\text { Difference }\end{array}$ & $p$ Value \\
\hline \multicolumn{7}{|l|}{ CCA-lumbar $\left({ }^{\circ}\right)$} \\
\hline OPEN vs MIS & 2.63 & 1.000 & 10.30 & 0.004 & 7.67 & 0.069 \\
\hline OPEN vs HYB & 1.30 & 1.000 & 11.50 & 0.002 & 9.77 & 0.016 \\
\hline HYB vs MIS & 1.33 & 1.000 & -1.21 & 1.000 & -2.11 & 1.000 \\
\hline \multicolumn{7}{|l|}{ CCA-thoracic $\left({ }^{\circ}\right)$} \\
\hline OPEN vs MIS & 11.90 & 0.008 & 9.31 & 0.031 & -2.59 & 0.914 \\
\hline OPEN vs HYB & 12.60 & 0.005 & 15.42 & $<0.001$ & 2.66 & 0.891 \\
\hline HYB vs MIS & -0.70 & 1.000 & -6.11 & 0.274 & -5.25 & 0.128 \\
\hline \multicolumn{7}{|l|}{$\operatorname{TK}\left({ }^{\circ}\right)$} \\
\hline OPEN vs MIS & 0.44 & 1.000 & 6.63 & 0.300 & 6.19 & 0.302 \\
\hline OPEN vs HYB & 1.16 & 1.000 & 2.82 & 1.000 & 0.57 & 1.000 \\
\hline HYB vs MIS & -0.72 & 1.000 & 3.81 & 1.000 & 5.62 & 0.420 \\
\hline \multicolumn{7}{|l|}{ PI-LL $\left({ }^{\circ}\right)$} \\
\hline OPEN vs MIS & 0.89 & 1.000 & -10.90 & 0.030 & -11.41 & 0.035 \\
\hline OPEN vs HYB & -5.08 & 0.969 & -4.66 & 0.893 & -2.03 & 1.000 \\
\hline HYB vs MIS & 5.97 & 0.723 & -6.24 & 0.508 & -9.38 & 0.174 \\
\hline \multicolumn{7}{|l|}{$\mathrm{PT}\left({ }^{\circ}\right)$} \\
\hline OPEN vs MIS & 0.04 & 1.000 & -0.69 & 1.000 & -0.84 & 1.000 \\
\hline OPEN vs HYB & -6.90 & 0.165 & -11.80 & 0.001 & -3.14 & 1.000 \\
\hline HYB vs MIS & 6.93 & 0.154 & 11.11 & 0.003 & 2.30 & 1.000 \\
\hline \multicolumn{7}{|l|}{ SVA (mm) } \\
\hline OPEN vs MIS & 36.62 & 0.100 & 3.93 & 1.000 & -32.68 & 0.087 \\
\hline OPEN vs HYB & 3.60 & 1.000 & 0.86 & 1.000 & -1.08 & 1.000 \\
\hline HYB vs MIS & 33.02 & 0.158 & 3.07 & 1.000 & -31.60 & 0.111 \\
\hline
\end{tabular}

* Boldface indicates significant values.

body levels fused (4.1) compared with the OPEN group (1.6) and the increased number of posterior levels fused (6.4) compared with the MIS group (5.2). The time required for repositioning between the lateral and prone positions also led to longer OR times. Although the average length of stay for the HYB group was shorter (4.5 days) than those for both the MIS (6.4 days) and OPEN (7.4 days) groups, the difference was not statistically significant. Further study is required to determine why the MIS subgroup had a similar length of hospital stay as the OPEN group.

Preoperatively, there were no significant differences in any of the parameters among the groups except for the thoracic CCA, which was smaller in the HYB group $\left(15^{\circ}\right)$ than in both the MIS $\left(16^{\circ}\right)$ and the OPEN $\left(28^{\circ}, \mathrm{p}=0.008\right)$ groups. Although the amount of change in the thoracic CCA was not significant, the postoperative thoracic CCA was (MIS $12^{\circ}, \mathrm{HYB}^{\circ}$, OPEN $21^{\circ}, \mathrm{p}<0.03$ ). Our analysis also determined a larger preoperative PI-LL mismatch for the HYB group $\left(26^{\circ}\right)$ than the MIS $\left(20^{\circ}\right)$ and OPEN $\left(20^{\circ}\right)$ groups, although the difference was not statistically significant. The amount of correction in the PI-LL mismatch was similar for each group and was not statistically significant $\left(3^{\circ}-14^{\circ}\right)$. Otherwise, pre- and postoperative values showed no differences among the groups. When examining preand postoperative values within the groups, however, certain factors become evident. All groups showed significant improvements in the lumbar CCA, although no improve-

TABLE 6: Preoperative and postoperative outcome measures among groups that underwent surgery for ASD*

\begin{tabular}{lcccccc}
\hline Group & VAS Back $(\Delta)$ & p Value & VAS Leg $(\Delta)$ & $p$ Value & ODI $(\Delta)$ & $p$ Value \\
\hline MIS & -3.7 & $<0.001$ & -0.7 & 0.564 & -20.7 & $<0.001$ \\
HYB & -4.5 & $<0.001$ & -2.4 & 0.057 & -13.5 & 0.004 \\
OPEN & -3.4 & 0.001 & -3.4 & 0.005 & -16.7 & 0.001 \\
\hline
\end{tabular}

* All had significant improvements in the outcome measures, except for VAS leg pain in the MIS group. Boldface indicates significant values. 


\section{Complications in spinal deformity surgery}

TABLE 7: Complications among patients who underwent surgery for ASD*

\begin{tabular}{lrrrrr}
\hline \multirow{2}{*}{ Type of Complication } & \multicolumn{5}{c}{$\%$ of Patients } \\
\cline { 2 - 4 } & MIS & HYB & OPEN & Overall & Chi-Square \\
\hline any complication & 30.0 & 47.4 & 62.5 & 45.5 & 0.147 \\
intraop complication & 0.0 & 5.3 & 25.0 & 9.1 & 0.027 \\
postop complication & 30.0 & 47.4 & 50.0 & 41.8 & 0.401 \\
major complication & 30.0 & 47.4 & 62.5 & 45.5 & 0.147 \\
minor complication & 0.0 & 21.1 & 25.0 & 14.5 & 0.065 \\
complication requiring surgery & 15.0 & 15.8 & 18.8 & 16.4 & 0.952 \\
DVT & 0.0 & 15.8 & 0.0 & 5.5 & 0.049 \\
PE & 0.0 & 10.5 & 0.0 & 3.6 & 0.140 \\
implant failure & 10.0 & 5.3 & 6.3 & 7.3 & 0.836 \\
neurological deficit & 5.0 & 15.8 & 6.3 & 9.1 & 0.451 \\
pneumonia & 0.0 & 0.0 & 6.3 & 1.8 & 0.289 \\
wound dehiscence & 0.0 & 5.3 & 0.0 & 1.8 & 0.381 \\
deep wound infection & 0.0 & 0.0 & 0.0 & 0.0 & 1.000 \\
proximal junctional kyphosis & 5.0 & 10.5 & 6.3 & 7.3 & 0.788 \\
other major complication & 5.0 & 10.5 & 25.0 & 12.7 & 0.189 \\
\hline
\end{tabular}

* The MIS group had the smallest and the OPEN group had the greatest percentage of patients with any, intraoperative, postoperative, major, and minor complications. Boldface indicates significant values.

ments were seen in PT. The HYB and OPEN groups showed significant improvement in the thoracic CCA, PILL mismatch, SVA, and TK. A critique of MIS has been its limitation in sagittal plane correction. We cannot draw conclusions in regard to this issue as enrolled patients were, in general, already globally balanced, and the MIS techniques could maintain it. The MIS group was the only group unable to correct the PI-LL mismatch to within $10^{\circ}$, leaving the patient with a spinopelvic mismatch. Advanced techniques of minimally invasive sagittal plane correction have been described in the literature..$^{1,13,14,35,37}$ For example, Deukmedjian et al. ${ }^{13}$ used the lateral transpsoas approach to release the anterior longitudinal ligament and place a hyperlordotic interbody cage in 7 patients, gaining an average of $17^{\circ}$ per level of anterior longitudinal ligament release. Similar results were described by Akbarnia et al. ${ }^{1}$ and Uribe et al., ${ }^{35}$ who discovered a $21^{\circ}$ increase in lumbar lordosis and a $10^{\circ}-20^{\circ}$ increase in segmental lordosis, respectively, with anterior column realignment. Wang and Madhavan ${ }^{37}$ used a posterior approach for a minimally invasive pedicle subtraction osteotomy, which resulted in a $15-\mathrm{cm}$ correction of the SVA. New innovations arise on a regular basis and will likely play a significant role in the future of MIS for ASD correction.

\section{Study Limitations}

The retrospective study design and review of the data are major limitations of this study. Furthermore, the multicenter nature of the study introduces a level of variability that is difficult to control for with respect to data collection and complication reporting. Given that 2-year follow-up reporting has become standard, the relatively short follow-up of 1 year in our cohort can be perceived as a shortfall of this interim analysis, as no conclusions can be made with regard to fusion status and long-term complications. However, the minimally invasive surgical procedures are relatively new, and no 2-year follow-up data for any large group of patients are currently available. Future studies with longer follow-ups are needed, and this cohort will be followed up for a longer time frame. Another disparity is the ability of the OPEN group to perform 3-column osteotomies for sagittal rebalancing, although only 3 of the patients in the OPEN group underwent an osteotomy. Given the different nature of the OPEN and MIS procedures, it is extremely difficult to match patients to create an exactly homogeneous population. The relatively small sample size is also a limitation. A power analysis revealed that this study could detect only large differences with $80 \%$ power, although this indicates that differences detected within this study should not be overlooked. To minimize these important differences and to further establish concrete evidence, a welldesigned prospective study is needed.

\section{Conclusions}

Our data suggest that type of surgical approach may impact complications. The MIS group had significantly fewer intraoperative complications than did either the HYB or OPEN groups. Radiographic and clinical improvements were similar for all groups. A prospective analysis of MIS techniques for deformity is warranted to examine complications more closely. If the goals of ASD surgery can be achieved, one should consider implementing less invasive techniques.

\section{Disclosure}

The authors report no conflict of interest concerning the materials or methods used in this study or the findings specified in this 
paper. Dr. Wang is a consultant for and holds a patent with DePuy Spine and is a consultant for Aesculap Spine. Dr. Park is a consultant for and receives royalties from Globus Medical and is a consultant for Medtronic. Dr. Uribe is a consultant for NuVasive. Dr. Kanter is a consultant for NuVasive and receives royalties from Lanx. Dr. Okonkwo receives royalties from Lanx. Dr. Deviren is a consultant for NuVasive, Stryker, and Biomet. Dr. Bess is a consultant for DePuy Spine and Medtronic. Dr. La Marca is a consultant for Globus Medical and Biomet, receives support from Globus Medical for non-study-related clinical or research effort, and holds a patent with Globus Medical. Dr. Mundis is a consultant for and receives royalties from NuVasive and $\mathrm{K} 2 \mathrm{M}$. Dr. Fu is a consultant for Medtronic. Dr. Mummaneni receives royalties from DePuy Spine, Quality Medical Publishing, and Thieme Publishing; has direct stock ownership in Spinicity; and receives honoraria from Globus Medical. Dr. Eastlack has direct stock ownership in NuVasive and Alphatec; is a consultant for DiFusion, Aesculap, Ulrich, Lanx, Alphatec, NuVasive, DePuy/Synthes, and RTI; holds patents with Globus Medical, Invuity, and NuTech; and has received clinical or research support from RTI, NuVasive, and Lanx for the study described. Dr. Anand is a consultant for and receives royalties from Medtronic, Globus Medical, and Baxano Surgical and receives royalties from NuVasive.

Author contributions to the study and manuscript preparation include the following. Conception and design: Uribe, Mummaneni, Mundis, Okonkwo, Kanter, Eastlack, Wang, Anand, Fessler, La Marca, Park, Lafage, Deviren, Bess, Shaffrey. Acquisition of data: Uribe, Mummaneni, Fu, Mundis, Okonkwo, Kanter, Eastlack, Wang, Anand, Fessler, La Marca, Park, Lafage, Deviren, Bess, Shaffrey. Analysis and interpretation of data: Uribe, Mummaneni, Fu, Mundis, Okonkwo, Kanter, Eastlack, Wang, Anand, Fessler, La Marca, Park, Lafage, Deviren, Bess, Shaffrey. Drafting the article: Deukmedjian, Uribe. Critically revising the article: Uribe, Mummaneni, Fu, Mundis, Okonkwo, Kanter, Eastlack, Wang, Anand, Fessler, La Marca, Park, Lafage, Deviren, Bess, Shaffrey. Reviewed submitted version of manuscript: Deukmedjian, Uribe, Fu, Shaffrey. Study supervision: Mummaneni, Shaffrey.

\section{References}

1. Akbarnia BA, Mundis GM Jr, Moazzaz P, Kabirian N, Bagheri R, Eastlack RK, et al: Anterior column realignment (ACR) for focal kyphotic spinal deformity using a lateral transpsoas approach and ALL release. J Spinal Disord Tech 27:29-39, 2014

2. Albert TJ, Purtill J, Mesa J, McIntosh T, Balderston RA: Health outcome assessment before and after adult deformity surgery. A prospective study. Spine (Phila Pa 1976) 20:2002-2005, 1995

3. Anand N, Baron EM, Thaiyananthan G, Khalsa K, Goldstein TB: Minimally invasive multilevel percutaneous correction and fusion for adult lumbar degenerative scoliosis: a technique and feasibility study. J Spinal Disord Tech 21:459-467, 2008

4. Auerbach JD, Lenke LG, Bridwell KH, Sehn JK, Milby AH, Bumpass D, et al: Major complications and comparison between 3-column osteotomy techniques in 105 consecutive spinal deformity procedures. Spine (Phila Pa 1976) 37:11981210, 2012

5. Berjano P, Lamartina C: Far lateral approaches (XLIF) in adult scoliosis. Eur Spine J 22 (Suppl 2):S242-S253, 2013

6. Bhagat S, Vozar V, Lutchman L, Crawford RJ, Rai AS: Morbidity and mortality in adult spinal deformity surgery: Norwich Spinal Unit experience. Eur Spine J 22 (Suppl 1):S42S46, 2013

7. Bradford DS, Tay BK, Hu SS: Adult scoliosis: surgical indications, operative management, complications, and outcomes. Spine (Phila Pa 1976) 24:2617-2629, 1999

8. Bridwell KH, Lewis SJ, Edwards C, Lenke LG, Iffrig TM, Berra A, et al: Complications and outcomes of pedicle subtraction osteotomies for fixed sagittal imbalance. Spine (Phila Pa 1976) 28:2093-2101, 2003
9. Cahill KS, Martinez JL, Wang MY, Vanni S, Levi AD: Motor nerve injuries following the minimally invasive lateral transpsoas approach. Clinical article. J Neurosurg Spine 17: 227-231, 2012

10. Cho SK, Bridwell KH, Lenke LG, Yi JS, Pahys JM, Zebala LP, et al: Major complications in revision adult deformity surgery: risk factors and clinical outcomes with 2- to 7-year follow-up. Spine (Phila Pa 1976) 37:489-500, 2012

11. Cloyd JM, Acosta FL Jr, Ames CP: Complications and outcomes of lumbar spine surgery in elderly people: a review of the literature. J Am Geriatr Soc 56:1318-1327, 2008

12. Dakwar E, Cardona RF, Smith DA, Uribe JS: Early outcomes and safety of the minimally invasive, lateral retroperitoneal transpsoas approach for adult degenerative scoliosis. Neurosurg Focus 28(3):E8, 2010

13. Deukmedjian AR, Dakwar E, Ahmadian A, Smith DA, Uribe JS: Early outcomes of minimally invasive anterior longitudinal ligament release for correction of sagittal imbalance in patients with adult spinal deformity. ScientificWorldJournal 2012:789698, 2012

14. Deukmedjian AR, Le TV, Baaj AA, Dakwar E, Smith DA, Uribe JS: Anterior longitudinal ligament release using the minimally invasive lateral retroperitoneal transpsoas approach: a cadaveric feasibility study and report of 4 clinical cases. Laboratory investigation. J Neurosurg Spine 17:530539, 2012

15. Edwards CC II, Bridwell KH, Patel A, Rinella AS, Berra A, Lenke LG: Long adult deformity fusions to L5 and the sacrum. A matched cohort analysis. Spine (Phila Pa 1976) 29: 1996-2005, 2004

16. Faciszewski T, Winter RB, Lonstein JE, Denis F, Johnson L: The surgical and medical perioperative complications of anterior spinal fusion surgery in the thoracic and lumbar spine in adults. A review of 1223 procedures. Spine (Phila Pa 1976) 20:1592-1599, 1995

17. Fan S, Hu Z, Zhao F, Zhao X, Huang Y, Fang X: Multifidus muscle changes and clinical effects of one-level posterior lumbar interbody fusion: minimally invasive procedure versus conventional open approach. Eur Spine J 19:316-324, 2010

18. Fessler RG, O'Toole JE, Eichholz KM, Perez-Cruet MJ: The development of minimally invasive spine surgery. Neurosurg Clin N Am 17:401-409, 2006

19. Glassman SD, Hamill CL, Bridwell KH, Schwab FJ, Dimar JR, Lowe TG: The impact of perioperative complications on clinical outcome in adult deformity surgery. Spine (Phila Pa 1976) 32:2764-2770, 2007

20. Isaacs RE, Hyde J, Goodrich JA, Rodgers WB, Phillips FM: A prospective, nonrandomized, multicenter evaluation of extreme lateral interbody fusion for the treatment of adult degenerative scoliosis: perioperative outcomes and complications. Spine (Phila Pa 1976) 35 (26 Suppl):S322-S330, 2010

21. Kim YB, Lenke LG, Kim YJ, Kim YW, Blanke K, Stobbs G, et al: The morbidity of an anterior thoracolumbar approach: adult spinal deformity patients with greater than five-year follow-up. Spine (Phila Pa 1976) 34:822-826, 2009

22. Kim YJ, Bridwell KH, Lenke LG, Rhim S, Cheh G: Pseudarthrosis in long adult spinal deformity instrumentation and fusion to the sacrum: prevalence and risk factor analysis of 144 cases. Spine (Phila Pa 1976) 31:2329-2336, 2006

23. Lapp MA, Bridwell KH, Lenke LG, Riew KD, Linville DA, Eck KR, et al: Long-term complications in adult spinal deformity patients having combined surgery a comparison of primary to revision patients. Spine (Phila Pa 1976) 26:973-983, 2001

24. Laws CJ, Coughlin DG, Lotz JC, Serhan HA, Hu SS: Direct lateral approach to lumbar fusion is a biomechanically equivalent alternative to the anterior approach: an in vitro study. Spine (Phila Pa 1976) 37:819-825, 2012

25. Linville DA, Bridwell KH, Lenke LG, Vedantam R, Leicht 


\section{Complications in spinal deformity surgery}

P: Complications in the adult spinal deformity patient having combined surgery. Does revision increase the risk? Spine (Phila Pa 1976) 24:355-363, 1999

26. McDonnell MF, Glassman SD, Dimar JR II, Puno RM, Johnson JR: Perioperative complications of anterior procedures on the spine. J Bone Joint Surg Am 78:839-847, 1996

27. Mummaneni PV, Tu TH, Ziewacz JE, Akinbo OC, Deviren V, Mundis GM: The role of minimally invasive techniques in the treatment of adult spinal deformity. Neurosurg Clin N Am 24:231-248, 2013

28. Parker SL, Lerner J, McGirt MJ: Effect of minimally invasive technique on return to work and narcotic use following transforaminal lumbar inter-body fusion: a review. Prof Case Manag 17:229-235, 2012

29. Pichelmann MA, Lenke LG, Bridwell KH, Good CR, O'Leary PT, Sides BA: Revision rates following primary adult spinal deformity surgery: six hundred forty-three consecutive patients followed-up to twenty-two years postoperative. Spine (Phila Pa 1976) 35:219-226, 2010

30. Scheufler KM, Cyron D, Dohmen H, Eckardt A: Less invasive surgical correction of adult degenerative scoliosis. Part II: Complications and clinical outcome. Neurosurgery 67:16091621,2010

31. Smith JS, Saulle D, Chen CJ, Lenke LG, Polly DW Jr, Kasliwal MK, et al: Rates and causes of mortality associated with spine surgery based on 108,419 procedures: a review of the Scoliosis Research Society Morbidity and Mortality Database. Spine (Phila Pa 1976) 37:1975-1982, 2012

32. Smith JS, Shaffrey CI, Glassman SD, Berven SH, Schwab FJ, Hamill CL, et al: Risk-benefit assessment of surgery for adult scoliosis: an analysis based on patient age. Spine (Phila Pa 1976) 36:817-824, 2011

33. Tormenti MJ, Maserati MB, Bonfield CM, Okonkwo DO, Kanter AS: Complications and radiographic correction in adult scoliosis following combined transpsoas extreme lateral interbody fusion and posterior pedicle screw instrumentation. Neurosurg Focus 28(3):E7, 2010

34. Turan A, Yang D, Bonilla A, Shiba A, Sessler DI, Saager L, et al: Morbidity and mortality after massive transfusion in pa- tients undergoing non-cardiac surgery. Can J Anaesth 60: 761-770, 2013

35. Uribe JS, Smith DA, Dakwar E, Baaj AA, Mundis GM, Turner $\mathrm{AW}$, et al: Lordosis restoration after anterior longitudinal ligament release and placement of lateral hyperlordotic interbody cages during the minimally invasive lateral transpsoas approach: a radiographic study in cadavers. Laboratory investigation. J Neurosurg Spine 17:476-485, 2012

36. Wang MY, Lerner J, Lesko J, McGirt MJ: Acute hospital costs after minimally invasive versus open lumbar interbody fusion: data from a US national database with 6106 patients. J Spinal Disord Tech 25:324-328, 2012

37. Wang MY, Madhavan K: Mini-open pedicle subtraction osteotomy: surgical technique. World Neurosurg [epub ahead of print], 2012

38. Wang MY, Mummaneni PV: Minimally invasive surgery for thoracolumbar spinal deformity: initial clinical experience with clinical and radiographic outcomes. Neurosurg Focus 28(3):E9, 2010

39. Wu WJ, Liang Y, Zhang XK, Cao P, Zheng T: Complications and clinical outcomes of minimally invasive transforaminal lumbar interbody fusion for the treatment of one- or two-level degenerative disc diseases of the lumbar spine in patients older than 65 years. Chin Med J (Engl) 125:2505-2510, 2012

Manuscript submitted November 19, 2013.

Accepted March 12, 2014.

Portions of this work were presented in abstract form at the Scoliosis Research Society's International Meeting on Advanced Spine Techniques (IMAST), held in Vancouver, BC, Canada, on July 10, 2013.

Please include this information when citing this paper: DOI: 10.3171/2014.3.FOCUS13534.

Address correspondence to: Armen R. Deukmedjian, M.D., Department of Neurosurgery and Brain Repair, University of South Florida, 2 Tampa General Circle, 7th Floor, Tampa, FL 33606. email: armendeuk@gmail.com. 